УДК 616.89-008.19:616.89.088.188:159.924.23:303.224.2:004.738-52-052

Для цитирования: Ворсина О.П., Петров А.А., Нелаев М.В., Нелаева И.А. Валидизация опросника оценки психоэмоционального состояния пользователей Интернета. Сибирский вестник психиатрии и наркологии. $2018 ; 4$ (101): 74-80. https://doi.org/10.26617/1810-3111-2018-4(101)-74-80

\title{
Валидизация опросника оценки психоэмоционального состояния пользователей Интернета
}

\author{
Ворсина О.П. ${ }^{1,2}$, Петров А.А. ${ }^{1}$, Нелаев М.В. ${ }^{1}$, Нелаева И.А. ${ }^{1}$ \\ ${ }^{1}$ Автономная некоммерческая организация Иркутский научно-практический центр \\ медицинской и сочиальной реабилитачии населения \\ 664025, Иркутск, ул. Горького, 11 \\ ${ }^{2}$ Иркутская государственная медииинская академия последипломного образования - филиал \\ Российской медицинской академии непрерывного профессионального образования \\ 664049, Иркутск, микрорайон Юбилейныий, 100
}

\section{PEЗЮME}

На сегодняшний день киберсуицид принимает характер особо значимой общественной и медицинской проблемы. Так называемые группы смерти, осуществляя свою деятельность через социальные сети, предопределяют беспрецедентный риск для жизни и здоровья подрастающего поколения. В связи с необходимостью использования надежных психометрических методик скрининг-диагностики суицидальных паттернов поведения среди пользователей глобальной сети в данной статье описывается процесс валидизации оригинального опросника оценки психоэмоционального состояния пользователей Интернета. Последний содержит 40 утверждений, сгруппированных в 8 доменов: «Депрессия», «Межличностные проблемы», «Отношения с родителями», «Негативная самооценка», «Чувство одиночества», «Демонстративность», «Аффективная неустойчивость», «Интернет-контент суицидального содержания». Посредством конфирматорного факторного анализа подтверждена хорошая согласованность структуры опросника. Определены балльные показатели уровней тяжести соответствующих нарушений. Заключение. Предложенный оригинальный опросник может быть эффективно использован для первичной диагностики суицидального поведения среди интернет-пользователей.

\section{Ключевые слова: опросник, группы смерти, синий кит, киберсуицид, валидизация.}

\section{ВВЕДЕНИЕ}

Проблема суицида - одна из наиболее острых и социально значимых междисциплинарных проблем, стоящих перед современной наукой [1]. В связи с информатизацией современного общества картина суицидального поведения существенно изменилась [2, 3]. В кризисные периоды пользователь Интернета, из любопытства или стремясь найти собеседников и обсудить свои проблемы, может легко зайти на сайты, пропагандирующие суицид [4]. Интернет как средство коммуникации может поощрять суицидальное поведение, изображая способы совершения самоубийства [5]. В виду последнего вопросы профилактики самоубийств посредством вовлечения в так называемые группы смерти в сети Интернет стали одной из самых широко обсуждаемых тем и в научных кругах, и в средствах массовой информации [6]. Активный рост киберугроз в нынешнем социуме определяет приоритеты и ставит перед каждым государством чрезвычайно актуальную задачу - необходимость обеспечения информационной безопасности [7]. На сегодняшний день, несмотря на активно принимаемые органами власти меры, проблема распространения суицидального контента в социальных сетях русскоязычного сегмента Интернета стоит предельно остро [8, 9]. Виртуальная игра «Синий кит» с ее хэш-тегами «Разбуди меня в 4:20», «Кит», «Тихий дом», «Ищу куратора», «Хочу в игру» взбудоражила сознание современных подростков и общественности [10].
Организаторы «суицидального квеста» умело играли на желании молодежи испытать себя и получить острые ощущения, предлагая своим жертвам испытать себя в выполнении заданий разного уровня экстремальности, подводящие к трагическому финалу. Параллельно проводилась их психологическая обработка, внушалась мысль о самоубийстве как благе. Обесценивался смысл жизни, дружбы, любви, привязанности к родным и близким $[11,12]$.

Киберсуицид означает самоубийство, деструктивную деятельность по самоуничтожению, которая совершается посредством и через Интернет, где на веб-сатах даются «советы», как покончить с собой. [13]. Ключевым маркером киберсуицида является онлайн-поиск информации о методах самоубийства [14].

Проблема виртуального суицида носит общемировой характер $[15,16]$. Исследователи подчеркивают, что участники современных деструктивных групп в социальных сетях приобретают черты, свойственные членам сект [17]. При этом связи между Интернетом и суицидами становятся все более значимыми по мере увеличения числа лиц, которых можно отнести к числу интернет-аддиктов [18]. Киберсуицид включает в себя 4 разновидности: 1) коммуникативныий (представляет собой виртуальное общение между группой людей, которых объединяет общая цель - коллективное самоубийство); 2) информационный (самоубийства, которые совершаются с использованием сведений, полученных через сетевые ресурсы); 3) аддиктивный (аутоагрессивые 
действия, возникающие в результате одиночества, эмоциональной напряженности, депрессии, заниженной самооценки и т.д.); 4) онлайн-киберсуицид (данный вид самоубийства либо совершается перед онлайн-аудиторией «игроков со смертью», либо процесс самоубийства широко обсуждается в переписке) [19]. На сегодняшний день виртуальные сети являются важнейшим социальным аспектом, модулирующим суицидальную активность среди детей, подростков и молодёжи [20].

Несмотря на беспрецедентную клиническую и социальную актуальность киберсуицида, на сегодняшний день отсутствуют надежные психометрические инструменты, позволяющие оценить суицидальный риск пользователей Интернета.

\section{ЦЕЛЬ ИССЛЕДОВАНИЯ}

Валидизация оригинального опросника оценки психоэмоционального состояния пользователей Интернета.

\section{МАТЕРИАЛ И МЕТОДЫ}

В исследовании опросника оценки психоэмоционального состояния пользователей Интернета приняли участие 1586 учащихся учебных заведений г. Иркутска и Иркутской области, из них 925 (58,3\%) девушек и $661(41,7 \%)$ юноша. Средний возраст респондентов составил $15 \pm 1,8$ года.

Bсе участники исследования заполняли анкету оригинального опросника психоэмоционального состояния пользователей Интернета (ООПСПИ), содержащего 40 утверждений. Структура теста включает 8 доменов: «Депрессия», «Межличностные проблемы», «Отношения с родителями», «Негативная самооценка», «Чувство одиночества», «Демонстративность», «Аффективная неустойчивость», «Интернет-контент суицидального содержания». Каждый домен представлен 5 утверждениями. Процесс ответа осуществляется по балльному принципу с использованием шкалы Лайкерта: 1 - «Полностью не согласен», 2 - «Не согласен», 3 - «Затрудняюсь ответить», 4 - «Согласен», 5 - «Полностью согласен». Подсчет результатов производился как по суммарному баллу опросника, так и по отдельным доменам. Респондентам предлагалось оценить свое психоэмоциональное состояние в течение последних 2 недель.

Первичная обработка полученных данных производилась при помощи описательной статистики. Корреляционный анализ проводился на основе непараметрической ранговой корреляции по Спирмену. Для проверки соответствия структуры собранных данных структуре методики применялся конфирматорный факторный анализ (CFA).

Внутренняя согласованность теста оценивалась посредством определения коэффициента альфа Кронбаха. С целью определения группы респондентов с наибольшими значениями по суммарному баллу и отдельным доменам был проведен анализ латентных профилей (LPA). Стандартизация показателей опросника осуществлялась определением уровней соответствующих показателей на основании нижнего и верхнего квартилей.

Уровень статистической значимости был зафиксирован на уровне вероятности ошибки 0,05. Статистическая обработка данных была выполнена с использованием пакетов прикладных программ Statistica 10, SPSS 10.0 и R.

\section{РЕЗУЛЬТАТЫ И ИХ ОБСУЖДЕНИЕ.}

Оказалось, что большинство доменов опросника связаны между собой умеренными связями $(0,20$ $0,54)$, и только между доменами «Чувство одиночества» и «Межличностные проблемы» наблюдается сильная связь $\left(\mathrm{r}_{\mathrm{s}}=0,74\right)$. Домен «Демонстративность» плохо коррелировал со всеми доменами опросника $(0,03-0,18)$ (табл. 1). Показатель альфа Кронбаха, равный 0,88 , свидетельствует о хорошей общей внутренней согласованности теста.

Коэффициенты корреляции (Спирмен) между доменами Оригинального опросника психоэмоционального состояния пользователей Интернета

\begin{tabular}{|c|c|c|c|c|c|c|c|c|}
\hline Домен & \begin{tabular}{|c} 
Депрес \\
прес- \\
сия
\end{tabular} & $\begin{array}{l}\text { Межлич- } \\
\text { ностные } \\
\text { проблемы }\end{array}$ & $\begin{array}{l}\text { Отноше- } \\
\text { ния с } \\
\text { родите- } \\
\text { лями }\end{array}$ & \begin{tabular}{|c|} 
Нега- \\
тивная \\
само- \\
оценка
\end{tabular} & $\begin{array}{c}\text { Чувство } \\
\text { рдиноче- } \\
\text { ства }\end{array}$ & $\begin{array}{l}\text { Демон- } \\
\text { стратив- } \\
\text { ность }\end{array}$ & $\begin{array}{c}\text { Аффектив- } \\
\text { ная не- } \\
\text { устойчи- } \\
\text { вость }\end{array}$ & \begin{tabular}{|c} 
Интернет- \\
контент суи- \\
цидального \\
содержания
\end{tabular} \\
\hline Депрессия & 1,00 & 0,53 & 0,34 & 0,52 & 0,54 & 0,11 & 0,43 & 0,43 \\
\hline Межличностные проблемы & 0,53 & 1,00 & 0,23 & 0,48 & 0,74 & 0,07 & 0,49 & 0,49 \\
\hline Отношения с родителями & 0,34 & 0,23 & 1,00 & 0,22 & 0,29 & 0,18 & 0,35 & 0,20 \\
\hline Негативная самооценка & 0,52 & 0,48 & 0,22 & 1,00 & 0,52 & 0,06 & 0,32 & 0,40 \\
\hline Чувство одиночества & 0,54 & 0,74 & 0,29 & 0,52 & 1,00 & 0,03 & 0,43 & 0,43 \\
\hline Демонстративность & 0,11 & 0,07 & 0,18 & 0,06 & 0,03 & 1,00 & 0,32 & 0,11 \\
\hline Аффективная неустойчивость & 0,43 & 0,49 & 0,35 & 0,32 & 0,43 & 0,32 & 1,00 & 0,37 \\
\hline Интернет-контент суицидального содержания & 0,43 & 0,49 & 0,20 & 0,40 & 0,43 & 0,11 & 0,37 & 1,00 \\
\hline
\end{tabular}

П р и м е ч а н и е. Все коэффициенты корреляции статистически значимы на уровне $\mathrm{p}<0,001$.

Для проверки соответствия внутренней структуры опросника предполагаемой модели был проведен конфирматорный факторный анализ с предположением о наличии 8 взаимозависимых доменов (рис. 1).
Анализ модели подтвердил её приемлемость (табл. 2). Индексы RMSEA $(0,056)$ и GFI, AGFI, CFI, TLI (большие 0,9) говорят о хорошем соответствии.

В рамках анализа латентных профилей было выделено четыре класса респондентов (рис. 2). 
Показатели соответствия модели, состоящей из 6 независимых факторов, исходным данным

\begin{tabular}{|l|c|}
\hline \multicolumn{1}{|c|}{ Индекс соответствия модели исходным данным } & Значение индекса \\
\hline CMIN/DF & 2,36 \\
\hline RMR & 0,086 \\
\hline GFI & 0,911 \\
\hline AGFI & 0,953 \\
\hline NFI & 0,903 \\
\hline TLI & 0,971 \\
\hline CFI & 0,964 \\
\hline RMSEA & 0,056 \\
\hline PCLOSE & 0,600 \\
\hline p, уровень значимости & $<0,0001$ \\
\hline
\end{tabular}

П р и м е ч а н и е. CMIN - хи-квадрат, DF - число степеней свободы, RMR (Root Mean Square Residual) - cpeднеквадратичный остаток, GFI (the goodness-of-fit-index) - критерий согласия; AGFI (adjusted goodness-of-fit index) - cкорректированный индекс пригодности, NFI (normed fix index) - скорректированный индекс пригодности, TLI (Tucke r-Lewis index) - индекс Такера Льюиса, CFI (comparative fix index) - сравнительный индекс согласия, RMSEA (root-mean-squared error of approximation) - среднеквадратическая ошибка оценки, PCLOSE (p of Close Fit) - односторонний тест значимости.

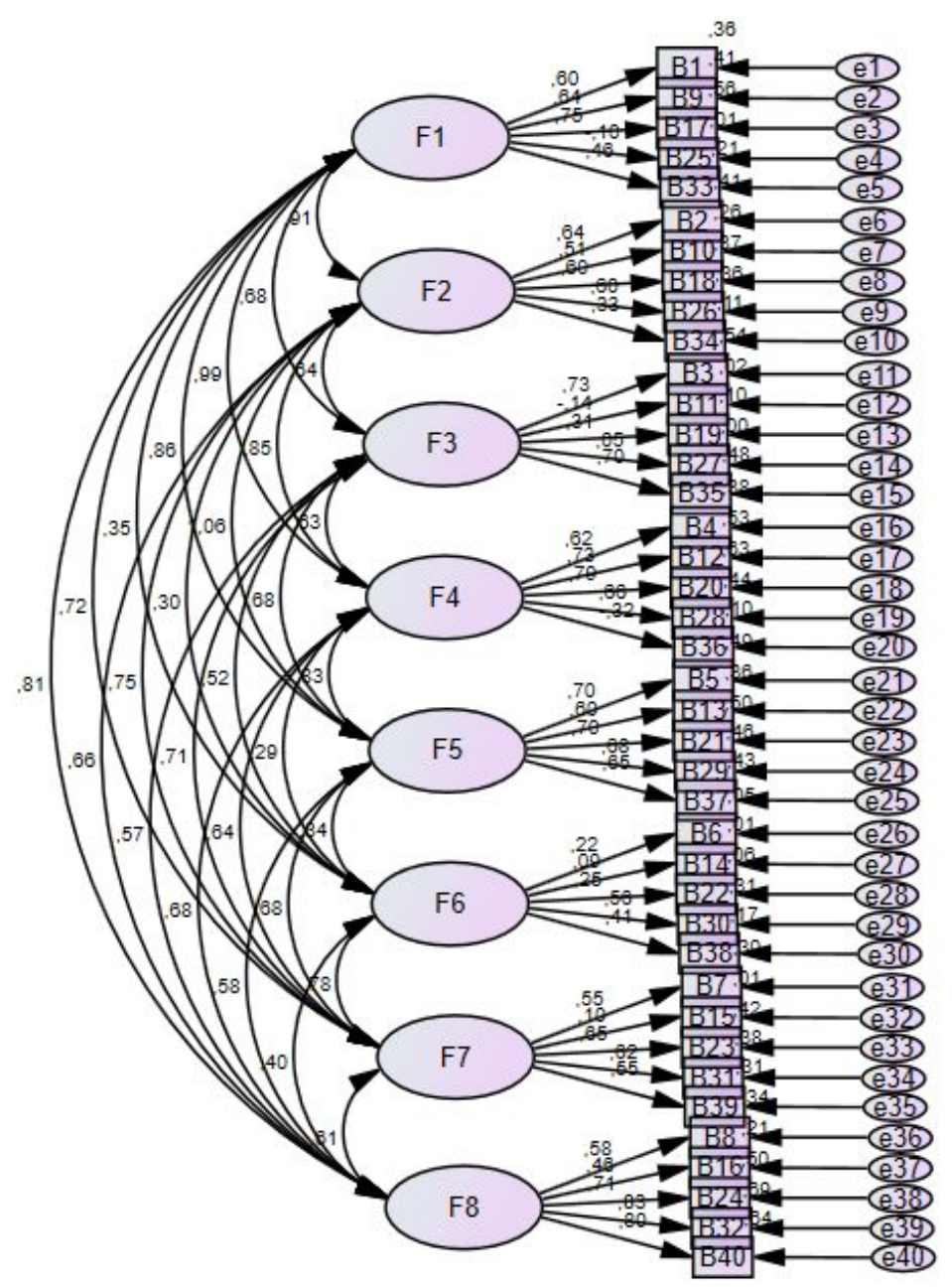

Р и с у н о к 1. Результаты оценки стандартизированных весовых коэффициентов для модели, предполагающей 8 взаимосвязанных факторов (доменов опросника)

(F1 - домен «Депрессия», F2 - домен «Межличностные проблемы», F3 - домен «Отношения с родителями», F4 - домен «Негативная самооценка», F5 - домен «Чувство одиночества», F6 - домен «Демонстративность»,

F7 - домен «Аффективная неустойчивость», F8 - домен «Интернет-контент суицидального содержания»)

Результаты показывают, что около трети опрошенных (36\%, profile 1) имеют крайне низкие показатели по всем доменам методики (в среднем от 5 до 12 баллов), что говорит о совершенной невыражен- ности негативных эмоциональных нарушений (ответ от 1 до 2 баллов по каждому утверждению опросника). Около половины респондентов (45\%, profile 3$)$ имеют низкие показатели по всем доменам (в сред- 
нем от 7 до 15 баллов), что свидетельствует о слабой выраженности негативных эмоциональных нарушений (ответ от 2 до 3 баллов по каждому утверждению). Таким образом, подавляющее большинство $(82 \%)$ респондентов не имели психоэмоциональных нарушений. Оставшиеся $18 \%$ респондентов разделились на две группы: группа средней выраженно- сти негативных эмоциональных состояний (profile 2, $16 \%$; в среднем от 11 до 17 баллов по доменам методики; от 3 до 4 баллов по каждому утверждению) и группа сильной выраженности негативных эмоциональных состояний - группа риска (profile 4, $2 \%$; в среднем от 13 до 22 баллов по доменам; от 3 до 5 баллов по каждому утверждению).

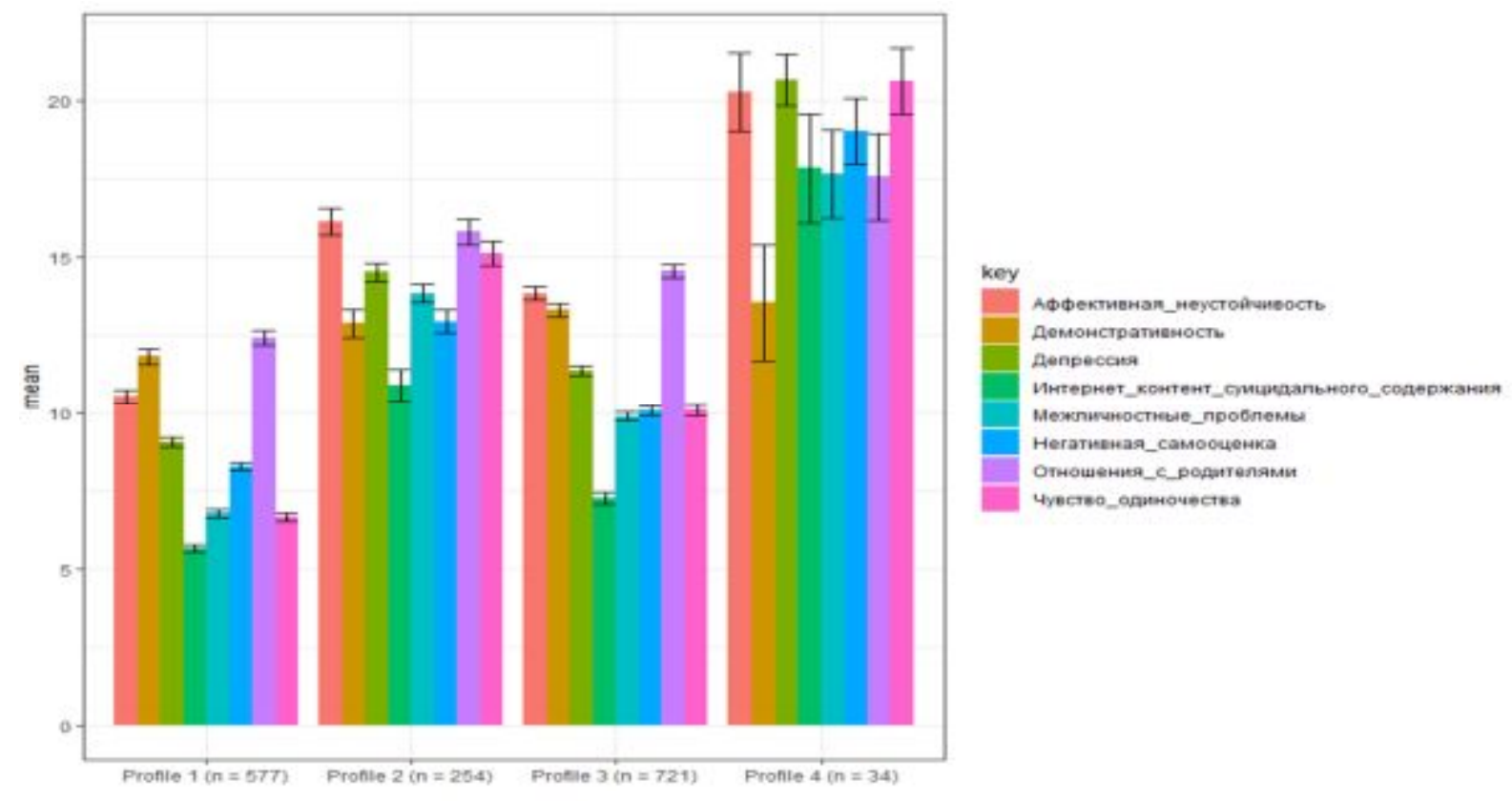

Р и с у н о к 2. Показатели доменов ООПСПИ для четырех классов респондентов, выделенных в результате анализа латентных профилей (LPA)

Ввиду наличия хорошей внутренней согласованности была проведена стандартизация опросника. Различные уровни выраженности соответствующих показателей определялись на основании значений нижнего и верхнего квартилей. Значения вплоть до нижнего квартиля (включая квартильное значение) были отнесены к низкому уровню выраженности.
Значения выше нижнего квартиля вплоть до верхнего квартиля (включая квартильное значение) были причислены к среднему уровню выраженности. Остальные значения были отнесены к высокому уровню выраженности, результаты представлены в таблице 3.

Значения шкал методики Опросник оценки эмоционального состояния пользователей Интернета в баллах для разных уровней выраженности соответствующего показателя

\begin{tabular}{|l|c|c|c|}
\hline \multicolumn{1}{|c|}{ Домен методики } & \multicolumn{3}{c|}{ Уровень } \\
\cline { 2 - 4 } & Низкий & Средний & Высокий \\
\hline Депрессия & $5-9$ & $10-13$ & $14-25$ \\
\hline Межличностные проблемы & $5-7$ & $8-11$ & $12-25$ \\
\hline Отношения с родителями & $5-12$ & $13-16$ & $17-25$ \\
\hline Негативная самооценка & $5-8$ & $9-11$ & $12-25$ \\
\hline Чувство одиночества & $5-7$ & $8-12$ & $13-25$ \\
\hline Демонстративность & $5-11$ & $12-15$ & $16-25$ \\
\hline Аффективная неустойчивость & $5-11$ & $12-15$ & $16-25$ \\
\hline Интернет-контент суицидального содержания & 5 & $6-9$ & $10-25$ \\
\hline Сумма баллов ООПСПИ & $25-75$ & $76-98$ & $99-200$ \\
\hline
\end{tabular}

В таблице 4 представлена описательная статистика для доменов оригинального опросника психоэмоционального состояния пользователей Интернета по выделенным уровням (низкий, средний, высокий). Приведенные в таблице результаты показывают, что низкий уровень выражен сильнее, чем высокий уровень. Это соответствует тому, что распределения полученных баллов являются несимметричными (большее количество значений расположено слева, т.е. приходится на диапазон низких значений). 
Распределение долей различных уровней выраженности по шкалам методики Опросник оценки эмоционального состояния пользователей Интернета

\begin{tabular}{|c|c|c|c|c|c|}
\hline Уровень выраженности & Всего & Доля, \% & Уровень выраженности & Всего & Доля, \% \\
\hline \multicolumn{3}{|c|}{ Депрессия } & \multicolumn{3}{|c|}{ Межличностные проблемы } \\
\hline Низкий уровень & 489 & $30,80 \%$ & Низкий уровень & 472 & $29,80 \%$ \\
\hline Средний уровень & 800 & $50,40 \%$ & Средний уровень & 729 & $46,00 \%$ \\
\hline Высокий уровень & 297 & $18,70 \%$ & Высокий уровень & 385 & $24,30 \%$ \\
\hline \multicolumn{3}{|c|}{ Отношения с родителями } & \multicolumn{3}{|c|}{ Негативная самооценка } \\
\hline Низкий уровень & 482 & $30,40 \%$ & Низкий уровень & 481 & $30,30 \%$ \\
\hline Средний уровень & 768 & $48,40 \%$ & Средний уровень & 726 & $45,80 \%$ \\
\hline Высокий уровень & 336 & $21,20 \%$ & Высокий уровень & 379 & $23,90 \%$ \\
\hline \multicolumn{3}{|c|}{ Чувство одиночества } & \multicolumn{3}{|c|}{ Демонстративность } \\
\hline Низкий уровень & 506 & $31,90 \%$ & Низкий уровень & 587 & $37,00 \%$ \\
\hline Средний уровень & 720 & $45,40 \%$ & Средний уровень & 692 & $43,60 \%$ \\
\hline Высокий уровень & 360 & $22,70 \%$ & Высокий уровень & 307 & $19,40 \%$ \\
\hline \multicolumn{3}{|c|}{ Аффективная неустойчивость } & \multicolumn{3}{|c|}{ Интернет-контент суицидального содержания } \\
\hline Низкий уровень & 549 & $34,60 \%$ & Низкий уровень & 680 & $42,90 \%$ \\
\hline Средний уровень & 645 & $40,70 \%$ & Средний уровень & 572 & $36,10 \%$ \\
\hline Высокий уровень & 392 & $24,70 \%$ & Высокий уровень & 334 & $21,10 \%$ \\
\hline \multicolumn{6}{|c|}{ Сумма баллов оригинального Опросника психоэмоционального состояния пользователей Интернета } \\
\hline Низкий уровень & & & 399 & & \\
\hline Средний уровень & & & 794 & & \\
\hline Высокий уровень & & & 393 & & \\
\hline
\end{tabular}

\section{ЗАКЛЮЧЕНИЕ}

Оригинальный опросник оценки психоэмоционального состояния пользователей Интернета может быть рекомендован к использованию в качестве скрининг-теста по определению предикторов суицидального риска среди активных пользователей мировой сети. Видится необходимым внедрение данной методики в практическую деятельность школьных и медицинских психологов, что в конечном итоге позволит эффективно снизить частоту киберсуицидов

\section{КОНФЛИКТ ИНТЕРЕСОВ}

Авторы заявляют об отсутствии конфликта интересов в связи с публикацией данной статьи.

\section{ИСТОЧНИК ФИНАНСИРОВАНИЯ}

Финансирование исследования по проверке валидизации оригинального опросника оценки психоэмоционального состояния пользователей Интернета осуществлено с использованием гранта Президента Российской Федерации на развитие гражданского общества, предоставленного Фондом президентских грантов в рамках реализации проекта «Интернет-группы смерти - реальная угроза современности».

\section{СООТВЕТСТВИЕ ПРИНЦИПАМ ЭТИКИ}

Исследование проведено с соблюдением норм современной биомедицинской этики и этических стандартов, разработанных в соответствии с Хельсинской декларацией ВМА (протокол заседания этического комитета АНО ИНПЦ МСРН № 16 от 8 июня 2017 г.).

\section{ЛИТЕРАТУРА}

1. Демдоуми Н.Ю., Денисов Ю.П. «Контент смерти»: проблема пропаганды суицида в русскоязычном интернете. Современные проблемы науки и образования. 2013; 4: 373-373.
2. Stamenković M. In full view-cybersuicide, hypervisual self and public showcase of death (for real). Istraživački medijski centar Podgorica. 2012: 73.

3. Cox G. Virtual suicide as decisive political act. Activist Media and Biopolitics. 2012: 103.

4. Ключко Е.И. Воздействие интернета на суицидальное поведение молодежи. Общество. Среда. Развитие. Terra Humana. 2014; 1 (30): 1-4.

5. Alao A.O., Soderberg M., Pohl E.L, Alao A.L. Cybersuicide: review of the role of the internet on suicide. CyberPsychology \& Behavior. 2006; 9; 4: 489-493.

6. Кириллова Т.В. Понятие жизнеспособности личности в контексте профилактики киберпреступлений против детей и подростков. Международный пенитенциарный журнал. 2017; 3; 2: 102-108.

7. Кочкина Э.Л. Определение понятия «киберпреступление». Отдельные виды киберпреступлений. Сибирские уголовнопроцессуальные и криминалистические чтения. Сборник научных трудов. Иркутск: БГУЭП, 2017.

8. Демдоуми Н.Ю., Денисов Ю.П. Проблема распространения «суицидального контента» в социальных сетях русскоязычного контента Интернета. Наука и образование XXI века: Сборник статей Международной научно-практической конференции. 2013; 31: 78-83.

9. Демдоуми Н.Ю., Денисов Ю.П. Распространение «суицидального контента» в киберпространстве русскоязычного интернета как проблема мультидисциплинарных исследований. Суицидология. 2014; 5; 2 (15): 47-54.

10. Клейберг Ю.А. Деструктивная интернет-игра «Синий кит» как девиантологический феномен: постановка проблемы. Пензенский психологический вестник. 2017; 1.

11. Бастрыкин А.И. Преступления против несовершеннолетних в интернет-пространстве: к вопросу о виктимологической профилактике и уголовно-правовой оценке. Всероссийский криминологический журнал. 2017; 1 (11): 5-12.

12. Сапоровская М.В., Максименко А.А., Тимонин А.Ю., Опарин Г.В. Психометрический анализ группы смерти «Синий Кит» социальной сети «В контакте» деструктивного он-лайн квест-ресурса. Аллея науки. 2017; 2 (11): 124-129.

13. Ахмиров А.И. Поиск смысла жизни в современном информационном пространстве. Исторические, философские, политические и юридические науки, культурология и искусствоведение. Bопросы теории и практики. Тамбов: Грамота, 2017; 9 (83): 22-24. 
14. Starcevic V., Aboujaoude E. Cyberchondria, cyberbullying, cybersuicide, cybersex: "new" psychopathologies for the 21 st century? World Psychiatry. 2015; 14; 1: 97-100.

15. Смирнова А.А., Захарова Т.Ю., Синогина Е.С. Киберугрозы безопасности подростков. Научно-педагогическое обозрение (Pedagogical Review). 2017; 3 (17): 99-107.

16. Sakamoto A. The Internet and Suicide. 2011.

17. Хмара Н.В., Хилькевич С.О., Левковский Р.В., Коваленко Д.А., Городецкая Л.Н. Влияние деструктивных групп через социальные сети на психическое развитие подростка. Проблемы здоровья и экологии. 2017; 4 (54): 79-83.

18. Короленко Ц.П., Дмитриева Н.В., Левина Л.В. К вопросу о влиянии интернет на суицидальное поведение. Ученые за- писки Санкт-Петербургского государственного института психологии и социальной работыл. 2014; 2: 103-107.

19. Делейчук Л.Э. Суицидальное поведение подростков как социальная проблема. Азимут научных исследований: педагогика и психология. 2017; 6; 2 (19): 312-314.

20. Демдоуми Н.Ю., Денисов Ю.П. Социальная сеть как аспект суицидальной активности среди детей и молодёжи (на основе анализа социальной сети «Вконтакте»). Тюменский медицинский журнал. 2013; 15 (3): 37-38.

Поступила в редакцию 10.05.2018 Утверждена к печати 6.11.2018

Ворсина Ольга Петровна, доктор медицинских наук, врач-психиатр, доцент кафедры психиатрии и наркологии Иркутская государственная медицинская академия последипломного образования - филиал ФГБОУ ДПО РМАНПО МЗ России.

Петров Александр Александрович, врач-психиатр АНО Иркутский научно-практический центр медицинской и социальной реабилитации населения.

Нелаев Михаил Вячеславович, врач-психиатр АНО Иркутский научно-практический центр медицинской и социальной реабилитации населения.

Нелаева Ирина Анатольевна, доктор психологических наук, директор АНО Иркутский научно-практический центр медицинской и социальной реабилитации населения.

Ворсина Ольга Петровна, ovorsina@mail.ru

УДК 616.89-008.19:616.89.088.188:159.924.23:303.224.2:004.738-52-052

For citation: Vorsina O.P., Petrov A.A., Nelaev M.V., Nelaeva I.A. Validation of the questionnaire for evaluation of psychoemotional state in Internet users. Siberian Herald of Psychiatry and Addiction Psychiatry. 2018; 4 (101): 74-80. https://doi.org/10.26617/1810-3111-2018-4(101)-74-80

\section{Validation of the questionnaire for evaluation of psycho-emotional state in Internet users}

\section{Vorsina O.P. ${ }^{1,}{ }^{2}$, Petrov A.A. ${ }^{1}$, Nelaev M.V. ${ }^{1}$, Nelaeva I.A. ${ }^{1}$}

${ }^{1}$ Autonomous Non-Profit Organization Irkutsk Scientific and Practical Center of Medical and Social Rehabilitation of the Population Gorky Street 11, 664025, Irkutsk, Russian Federation

${ }^{2}$ Irkutsk State Medical Academy of Postgraduate Education - a branch of the Russian State Medical Academy

Russian Medical Academy of Continuing Vocational Education

Yubileiny Catchment Area 100, 664049, Irkutsk, Russian Federation

\section{ABSTRACT}

Nowadays, cybersuicide shapes a particularly significant social and medical problem. The so-called "groups of death" carrying out their activities through social networks predetermine an unprecedented risk to the life and health of the younger generation. In connection with the need to use reliable psychometric methods of screening and diagnosing suicidal behavior patterns among users of the global network, this article describes the process of validation of the original questionnaire assessing the psycho-emotional state of Internet users. The latter contains 40 statements grouped into 8 domains: "Depression", "Interpersonal Problems", "Relationship with Parents", "Negative Self-Evaluation", "Sense of Solitude", "Demonstrativeness", "Affective Instability", "Internet Content of Suicidal Content". The confirmator factor analysis confirms the good consistency of the structure of the questionnaire. The score of the severity levels of the corresponding disturbances are identified. Conclusion: The proposed original questionnaire can be effectively used for the initial diagnosis of suicidal behavior among Internet users.

\section{Keywords: questionnaire, death groups, blue whale, cybersuicide, validation.}

\section{REFERENCES}

1. Demdoumi N.Yu., Denisov Yu.P. "Kontent smerti”: problema propagandy suicida $\mathrm{v}$ russkojazychnom internete ["The Content of death": the problem of propaganda of suicide in the Russianspeaking Internet]. Sovremennye problemy nauki i obrazovaniya - Modern Problems of Science and Education. 2013; 4: 373-373 (in Russian).

2. Stamenković M [In full view-cybersuicide, hypervisual self and public showcase of death (for real)]. Istraživački medijski centar Podgorica. 2012: 73 .

3. Cox G. Virtual suicide as decisive political act. Activist Media and Biopolitics. 2012: 103.

4. Klyuchko E.I. Vozdejstvie interneta na suicidal'noe povedenie molodezhi [The impact of the Internet on youth suicidal behavior]. Obshhestvo. Sreda. Razvitie (Terra Humana) - Society. En- vironment. Development. Terra Humana. 2014; 1 (30): 1-4 (in Russian).

5. Alao A.O., Soderberg M., Pohl E.L, Alao A.L. Cybersuicide: review of the role of the internet on suicide. CyberPsychology \& Behavior. 2006; 9; 4: 489-493.

6. Kirillova T.V. Ponjatie zhiznesposobnosti lichnosti v kontekste profilaktiki kiberprestuplenij protiv detej i podrostkov [The concept of personal vitality in the context of prevention of cybercrime against children and adolescents]. Mezhdunarodnyj penitenciarnyj zhurnal - International Penitentiary Journal. 2017; 3; 2: 102-108 (in Russian).

7. Kochkina E.L. Opredelenie ponjatija "kiberprestuplenie". Otdel'nye vidy kiberprestuplenij [The definition of "cybercrime". Separate types of cybercrime]. Sibirskie ugolovno- 
processual'nye i kriminalisticheskie chtenija - Siberian Criminal Procedure and Forensic Readings. Irkutsk, 2017 (in Russian).

8. Demdoumi N.Yu., Denisov Yu.P. Problema rasprostranenija "suicidal'nogo kontenta" v social'nyh setjah russkojazychnogo kontenta Interneta [The problem of the distribution of "suicidal content" in the social networks of the Russian-language Internet content]. Nauka i obrazovanie XXI veka: Sbornik statej Mezhdunarodnoj nauchno-prakticheskoj konferencii - Science and Education of the XXI Century: Collection of Articles of the International Scientific and Practical Conference. 2013; 31: 78 83 (in Russian).

9. Demdoumi N.Yu., Denisov Yu.P. Rasprostranenie "suicidal'nogo kontenta" v kiberprostranstve russkojazychnogo interneta kak problema mul'tidisciplinarnyh issledovanij [Distribution of "suicidal content" in the cyberspace of the Russian-speaking Internet as a problem of multidisciplinary research]. Suicidologija - Suicidology. 2014; 5; 2 (15): 47-54 (in Russian).

10. Kleiberg Yu.A. Destruktivnaja internet-igra «Smnij kit» kak deviantologicheskij fenomen: postanovka problemy [Destructive Internet game "See the Whale" as a deviantological phenomenon: problem statement]. Penzenskij psihologicheskij vestnik Penza Psychological Herald. 2017; 1 (in Russian).

11. Bastrykin A.I. Prestuplenija protiv nesovershennoletnih v internet-prostranstve: $\mathrm{k}$ voprosu o viktimologicheskoj profilaktike i ugolovno-pravovoj ocenke [Crimes against minors in the Internet space: on the issue of victimological prevention and criminal legal assessment]. Vserossijskij kriminologicheskij zhurnal Russian Journal of Criminology. 2017; 1 (11): 5-12 (in Russian).

12. Saporovskaya M.V., Maksimenko A.A., Timonin A.Yu., Oparin G.V. Psihometricheskij analiz gruppy smerti "Sinij Kit" social'noj seti "V kontakte" destruktivnogo on-lajn kvest-resursa [Psychometric analysis of the "Blue Kit" death group of the Vkontakte social network of a destructive on-line quest - resource]. Alleja nauki - Alley of Science. 2017; 2 (11): 124-129 (in Russian).

13. Ahmirov A.I. Poisk smysla zhizni v sovremennom informacionnom prostranstve [Search for the meaning of life in the modern information space]. Istoricheskie, filosofskie, politicheskie i juridicheskie nauki, kul'turologija i iskusstvovedenie [Historical, philosophical, political and legal sciences, cultural studies and art history]. Voprosy teorii i praktiki - Issues of Theory and Practice. Tambov: Gramota, 2017; 9 (83): 22-24 (in Russian).

14. Starcevic V., Aboujaoude E. Cyberchondria, cyberbullying, cybersuicide, cybersex: "new" psychopathologies for the $21 \mathrm{st}$ century? World Psychiatry. 2015; 14; 1: 97-100.

15. Smirnova A.A., Zakharova T.Yu., Sinogina E.S. Kiberugrozy bezopasnosti podrostkov [Adolescent security cyber threats]. Nauchno-pedagogicheskoe obozrenie. Pedagogical Review Scientific and Pedagogical Review. Pedagogical Review. 2017; 3 (17): 99-107 (in Russian).

16. Sakamoto A. The Internet and Suicide. 2011.

17. Hmara N.V., Hilkevich S.O., Levkovsky R.V., Kovalenko D.A., Gorodetskaya L.N [Vlijanie destruktivnyh grupp cherez social'nye seti na psihicheskoe razvitie podrostka [The impact of destructive groups through social networks on the mental development of adolescents]. Problemy zdorov'ja i jekologii-Health and Ecology Problems. 2017; 4 (54): 79-83 (in Russian).

18. Korolenko C.P., Dmitrieva N.V., Levina L.V. K voprosu o vlijanii internet na suicidal'noe povedenie [On the issue of the impact of the Internet on suicidal behavior]. Uchenye zapiski SanktPeterburgskogo gosudarstvennogo instituta psihologii $i$ social'noj rabot - Scientific Notes of the St. Petersburg State Institute of Psychology and Social Work. 2014; 2: 103-107 (in Russian).

19. Deleycuk L.E. Suicidal'noe povedenie podrostkov kak social'naja problema [Teen suicidal behavior as a social problem]. Azimut nauchnyh issledovanij: pedagogika i psihologija - Azimuth of Scientific Research: Pedagogy and Psychology. 2017; 6; 2 (19): 312-314 (in Russian).

20. Demdoumi N.Yu. Social'naja set' kak aspekt suicidal'noj aktivnosti sredi detej i molodjozhi (na osnove analiza social'noj seti "Vkontakte") [Social network as an aspect of suicidal activity among children and young people (based on the analysis of the social network "Vkontakte")]. Tjumenskij medicinskij zhurnal Tyumen Medical Journal. 2013; 15 (3): 37-38 (in Russian).

Received May 10.2018 Accepted November 6.2018

Vorsina Olga P., MD, psychiatrist, Autonomous Non-Profit Organization Irkutsk Scientific and Practical Center of Medical and Social Rehabilitation of the Population, Irkutsk, Russian Federation; Irkutsk State Medical Academy of Postgraduate Education - a branch of the Russian State Medical Academy, Russian Medical Academy of Continuing Vocational Education, Irkutsk, Russian Federation.

Petrov Alexander A., psychiatrist, Autonomous Non-Profit Organization Irkutsk Scientific and Practical Center of Medical and Social Rehabilitation of the Population, Irkutsk, Russian Federation.

Nelaev Mikhail V., psychiatrist, Autonomous Non-Profit Organization Irkutsk Scientific and Practical Center of Medical and Social Rehabilitation of the Population, Irkutsk, Russian Federation.

Nelaeva Irina A., Doctor of Psychology, Director of the Autonomous Non-Profit Organization Irkutsk Scientific and Practical Center of Medical and Social Rehabilitation of the Population, Irkutsk, Russian Federation. 